\title{
Architecture students and research courses: are they aligned? Students' attitude towards research courses
}

\author{
S. J. T. Jansen ${ }^{1}$ (D) . H. J. F. M. Boumeester ${ }^{1}$ - R. M. Rooij ${ }^{2}$
}

Received: 22 October 2020 / Accepted: 23 July 2021 / Published online: 29 July 2021

(C) The Author(s) 2021

\begin{abstract}
Research courses are part of many higher education curricula. However, students' attitudes towards statistics and research courses tend to be negative. One way to measure students' attitude is with the Revised-Attitudes Towards Research scale (R-ATR). The current study examined: (1) the internal reliability of the R-ATR, (2) the attitude of Dutch second-year architecture students towards research courses, and (3) whether attitude is related to age and gender. It was found that the R-ATR has good internal reliability and that Dutch second-year architecture students' attitude towards research courses is reasonably favorable. Students generally acknowledge the usefulness of research courses and do not feel anxious, but find them stressful and difficult to some extent and do not enjoy them. Further analyses showed three types of students: relaxed students, virtuous students and worried students, who each require a different approach to improving their attitude towards research courses. No relationship emerged between attitude and age or gender, but female students considered research courses somewhat more useful. Providing a research-friendly, enjoyable, and supportive environment might improve students' attitude towards research courses.
\end{abstract}

Keywords Attitude - Anxiety · Architecture education · Research courses · Usefulness

\section{Introduction}

In many curricula in higher education, research courses are included. Research can be defined as the activity of collecting and analyzing information in a systematic way in order to increase the knowledge of the phenomenon under study (Leedy \& Ormrod, 2010). However, students often do not like to take research courses (Papanastasiou, 2005) and previous studies have shown that students' attitudes towards statistics and research courses tend to be negative (Shaukat et al., 2014). For example, Murtonen (2005) found that $42 \%$ of Finnish students in a sample had a negative attitude towards quantitative research methods.

S. J. T. Jansen

s.j.t.jansen@tudelft.nl

1 Department of Management in the Built Environment, Faculty of Architecture and the Built Environment, Delft University of Technology, Delft, The Netherlands

2 Department of Urbanism, Faculty of Architecture and the Built Environment, Delft University of Technology, Delft, The Netherlands 
Students might not feel empowered to understand and use research or they might find such courses demanding and difficult (Murtonen, 2005; Papanastasiou, 2014). Students also might not understand the concept of research and its importance for their future professional career (Maqsood et al., 2019; Shaukat et al., 2014). Finally, students might confuse doing research with doing statistics and might therefore fear that poor quantitative skills could prevent them from doing well in research courses (Papanastasiou, 2014). 'Statistics anxiety' can yield problems in many applied sciences where statistics and methodology classes are both mandatory and necessary to provide essential academic skills (Strobl et al., 2010).

One way of measuring students' opinions towards research courses is by examining their attitude. An attitude can be defined as "a psychological tendency that is expressed by evaluating a particular entity with some degree of favour or disfavour" (Eagly \& Chaiken, 1993, p. 1). Attitudes are important because a positive attitude helps students to master a particular teaching program, such as a professional skills program (Byrne et al., 2020) or science learning (Ebenezer et al., 2020). A negative attitude might serve as an obstacle to learning and might be associated with poor achievement results in research courses (Murtonen, 2005; Papanastasiou, 2005). Students' research attitude has also been found to be related to the intention to carry out research as professionals after graduation (Griffioen, 2019). This is important for vocationally-oriented higher education. Generally, attitude research in education focuses on students' attitudes towards science (e.g. Kennedy et al., 2020; Tseng et al., 2013; see Aguilera \& Perales-Palacios, 2020 for a meta-analysis), towards statistics (e.g. Ashaari et al., 2011; Coetzee \& van der Merwe, 2010; DeVaney, 2010; Griffith et al., 2012; Hannigan et al., 2014; Nguyen et al., 2015; Strobl et al., 2010; Zan \& Martino, 2007) and towards research courses (e.g. Deepa, 2014; Murtonen, 2005; Oguan et al., 2014; Papanastasiou, 2005, 2014; Shaukat et al., 2014; Siemens et al., 2010).

Papanastasiou (2005) developed an Attitudes towards Research scale consisting of five domains: (1) usefulness of research in professional life, (2) research anxiety, (3) positive attitudes towards research, (4) usefulness of research in students' lives and (5) difficulty of research. These domains agree largely with the constructs that have been found to be important for attitudes towards Science, Technology, Engineering and Mathematics (STEM) topics: enjoyment, relevance, anticipated benefits and past successes and achievements (Kennedy et al., 2020). Papanastasiou (2005) concluded that students generally find research useful in their professional lives, as well as in their personal lives, and that they do not find research courses very difficult. However, the students also tended to have a negative attitude and to feel anxious towards research courses. In 2014, Papanastasiou published a revised version of the Attitude towards Research scale for which 19 items were deleted and the domains of Usefulness of research in student's life and Difficulty of research were no longer included.

Some researchers have explored whether there is relationship between age and gender and attitude towards research courses. Zan and Martino (2007), Siemens et al. (2010) and Shaukat et al. (2014) showed that older students generally have a more-positive attitude towards research courses than younger students. Shaukat et al. (2014) explain their finding by arguing that students aged 30+ years students are in a crucial stage of their careers and therefore might give high priority to research. They are also more frequently actually involved in doing research or have research experience. Deepa (2014), Shaukat et al. (2014) and Maqsood et al. (2019) reported that men generally had a somewhat more-positive attitude towards research (usefulness) than females. Shaukat et al. (2014) explain the difference by arguing that males are more inclined towards mathematics, statistics and economics than females and that males prefer professions that demand good skills in mathematics 
and research, such as business, management and accounting. As far as we are aware, the relationship between age, gender and the attitude towards research courses has not been examined using the Revised-Attitudes Towards Research scale. Papanastasiou (2014) indicated that the study sample mainly consisted of females, and therefore the relationship between gender and the attitude towards research courses could not be examined. Furthermore, Papanastasiou (2014) recommended studying the relationship between attitude towards research and age.

The current study focused on Dutch architecture ${ }^{1}$ students at Delft University of Technology (TU Delft). Architecture (in Dutch: 'Bouwkunde') is a practical engineering science that focuses on understanding and solving socio-spatial-technical issues in the built environment. Academic skills for architects focus to a large extent on assessing design situations, informing design decisions, underpinning design solutions, and critically reflecting on design processes and design products (Lousberg et al., 2019). Based on our experience in teaching research courses at this faculty, we have the impression that many students have a relatively-negative attitude towards research courses, which could be explained in a number of ways. Firstly, architecture students generally aim to work as designers after their graduation and not as researchers. Therefore research courses might not seem directly relevant or useful for the students' future career. Secondly, architecture students are generally visually orientated and have rather creative minds, capacities that seem less compatible with the more-strict rules and systematic approach of doing research. The fundamental difference between the creative process associated with design situations and the relative rigidity of the research protocol can deprive students of the pleasure in their research course or even instill fear.

It is important to determine students' attitude towards research courses as well as to examine underlying latent factors, such as perceived usefulness, pleasurableness and anxiety. This could help in understanding students' difficulties and finding ways to overcome the multiplicity of reasons behind these difficulties (Papanastasiou, 2005). Based on information about whether and to what extent students' attitudes need to be changed, appropriate interventions could be developed to positively influence attitudes and eventually mastery of the desired skills (Byrne et al., 2020; Shaukat et al., 2014).

The goal of this study was twofold. The first goal was to provide an overview of secondyear bachelor architecture students' attitude towards research courses and to examine in more depth their perceptions of usefulness, anxiety towards and positive feelings regarding these courses. This could help in adapting a course to align it better with students' wishes and needs. For example, one can think about emphasizing the usefulness of research courses for the students' future careers by inviting architects to give a lecture on the way in which they use research in their daily practice. Feelings of anxiety could be lowered by offering extra opportunities for asking questions to those who need them. Positive feelings could be enhanced by changing the way in which the study material is conveyed by, for example, using new media, videos or serious games. Because the attitude cannot be reliably examined unless the instrument has been validated, the second goal was to validate the Revised-Attitudes Towards Research scale in a Dutch context among second-year bachelor

\footnotetext{
1 The full name of the bachelor program is Architecture, Urbanism \& Building Sciences (in Dutch: 'Bouwkunde'). It is a so-called broad bachelor. We will use the word architecture in the article, but the program covers the full range of subdisciplines of the built environment: architectural design, building technology, landscape architecture, urban design and planning, construction management, real estate development, housing and geo information.
} 
architecture students. The study started by examining the internal reliability of the R-ATR scale. The research questions were:

(1) What is the internal reliability of the Revised-Attitudes Towards Research scale in a Dutch second-year architecture student sample?

(2) What is the attitude of Dutch second-year architecture students towards research courses and what are their perceptions of usefulness, anxiety towards and positive feelings regarding these courses?

(3) Is the attitude towards research courses related to age and gender?

\section{Respondents and methods}

\section{Respondents}

The three-year $\left(180\right.$ ECTS $\left.^{2}\right)$ bachelor program Architecture, Urbanism \& Building Sciences focuses on six major learning tracks: Technology; Fundamentals; Society, Process and Practice; Design; Academic Skills and Representation, Visualization and Form (TU Delft, 2020). The program is structured into a fall and spring semester $(2 \times 20$ weeks $)$ and two quarters within each semester $(4 \times 10$ weeks). Each 15 ECTS quarter consists of one studio project and one course $(10+5$ ECTS $)$ or three courses $(5+5+5$ ECTS $)$. Although research skills play a role in education for the other learning tracks, this role is most clear and obvious for the Academic Skills learning track. This track consists of three 5 ECTS courses: Architecture as a scientific discipline in the first year, Empirical research project in the second year and Design reflection in the third year's graduation semester.

The survey was offered in February 2019 just before the start of the course Empirical research project, which is obligatory in the second year of the educational program. The course has two components: six weeks of lectures and working groups to teach students the basics of statistics; and 10 weeks of students performing a quantitative empirical study in groups of four students (project-based learning) on a research topic related to housing. This empirical project covers all aspects of research: a literature study, designing the study (research problem, research goal, research questions, conceptual model, population and sample, questionnaire), data collection using an online survey, statistical data analyses (using the knowledge on statistics obtained in the first six weeks), reporting and reflection.

\section{Revised-attitudes towards research scale}

The Revised-Attitudes Towards Research Scale (R-ATR; Papanastasiou, 2014) is a selfreport measure that consists of 13 Likert items, with response categories ranging from 1 Strongly Disagree to 7 Strongly Agree. The 13 items load on three underlying latent factors: Research usefulness (4 items), Research anxiety (5 items) and Positive research predispositions (4 items). The factor Research usefulness measures the student's perceptions of the usefulness of research in their study and subsequent professional lives. The Research

\footnotetext{
${ }^{2}$ ECTS: European Credit Transfer System. In Delft 1, ECTS represents $28 \mathrm{~h}$ of study, including contact time with faculty staff (workshops, seminars, lectures, studio work etc.), self-study time and untutored group work.
} 
anxiety factor measures the negative feelings of stress and anxiety in relation to research courses. The Positive research predispositions factor measures the existence of positive feelings and interest towards research courses. The R-ATR has good psychometric properties (Papanastasiou, 2014). The Research usefulness factor covers the cognitive aspects and the Research anxiety factor and Positive research predisposition factor cover the negative and positive affective aspects of attitude.

\section{The survey}

The 13 questions as formulated by Papanastasiou (2014) were translated from English to Dutch by four researchers independently. The results of the translations were compared and inconsistencies between translations were discussed until unanimity was established.

As well as the R-ATR instrument, the survey contained two socio-demographic questions (gender and age), one question on students' experience with other modules in the curriculum and one question on perceived ability with various research techniques (e.g. statistical analysis, geodata analysis, interview techniques and case-study research). Finally, one question on the importance of the various research techniques for the architecture curriculum was added.

\section{Statistical analysis}

The first research question involved the internal reliability of the R-ATR, which was explored by confirmatory factor analysis (structural equation modelling using AMOS version 25). The latent factors were allowed to correlate, but the residuals were not allowed to correlate. The items were only allowed to load on their respective factors. The model fit was determined using the Root Mean Square Error of Approximation (RMSEA), with the values of $0.01,0.05$, and 0.08 indicating excellent, good, and mediocre fit, respectively. Subsequently, the value of Cronbach's alpha coefficient was calculated to check the internal reliability of the items that theoretically make up for the three factors: Research usefulness (4 items), Research anxiety (5 items) and Positive research predispositions (4 items). Generally, a value of at least 0.70 is assumed to reflect sufficient internal reliability.

The second research question involved students' attitude towards research courses. Means and standard deviations were calculated for each of the 13 items. A cluster analysis (TwoStep cluster) was performed in order to explore whether there were groups of students with similar attitudes. The combined information from the two different methods (factor analysis and cluster analysis) provided greater insight into the three underlying aspects of attitude towards research courses.

The third research question involved relationships between attitude towards research courses and age and gender. Pearson correlations were used to determine the relationship between each of the 13 items and each of the three latent factors to age. An independentsample $t$-test was used to examine gender differences in each of the 13 items and each of the three factors to gender. An analysis of variance (ANOVA) was used to examine whether the three clusters of students, detected using the TwoStep cluster analysis, differed from each other with regard to mean age. A $\chi^{2}$ test was used to examine whether cluster membership was related to gender.

Likert scales like the ones used in this study are frequently not normally distributed. Both the Kolmogorov-Smirnov and the Shapiro-Wilks test showed that the 13 propositions were not normally distributed. When we calculated standardized skewness and 
kurtosis scores according to Field (2009; p. 139), seven items had standardized skewness scores $<1.96$; four items had scores $>1.96$ but below 2.58; and two items had skewness scores above 2.58. The highest standardized skewness score was 2.64. Eleven items had standardized kurtosis scores < 1.96; and two items had scores higher than 1.96, but below 2.58 (highest kurtosis is 2.24). Overall, normality was violated, but not to a very large extent. It is usually assumed that, with large enough sample sizes $(>40)$, violation of the normality assumption would not cause major problems because the sampling distribution of the means would be more or less normal (Field 2009, p. 156).

\section{Results}

\section{Respondents}

Four hundred and seventy-two (472) students who had enrolled for the course Empirical research project, but had not yet started, received an e-mail with an invitation and a link to the internet questionnaire. The survey was filled out by 80 students or a response rate of $17 \%$. More than half of respondents were female $(n=44 ; 56 \%), 44 \%$ were male $(n=34)$ and 2 respondents did not answer the question on gender. Ages ranged from 19 to 28 years (mean $=20.6$ years), with the exception of one student being 47 years of age. In comparison, the mean age of all second-year bachelor Architecture students in the year 2018-2019 was 20.0 years and the gender distribution was 50/50 $(n=364)$. The difference between the number of enrolled students $(n=472)$ and officially registered second-year bachelor students $(n=364)$ can be explained by the fact that many students who need to re-sit the aforementioned statistics examination that is part of the course had already participated in the research project.

\section{Internal reliability of the R-ATR scale for a Dutch second-year architecture student sample}

To examine the internal reliability of the R-ATR scale, a model was built and analyzed using AMOS version 25. The three latent factors were allowed to correlate with each other (Papanastasiou, 2014), the items were deemed to load only on their respective factors, and the errors were not allowed to correlate. The RMSEA fit of the resulting model was 0.069, which indicates a mediocre fit. Taking the above-mentioned restrictions into account, this result is quite satisfactory.

The results are summarized in Table 1. The standardized estimates for the four items that together make up for the Research usefulness factor all have about the same magnitude (between 0.70 and 0.76), indicating that they are tightly and to about the same extent related to their latent factor. For the factor Research anxiety, the standardized estimates ranged between 0.40 and 0.95 . The low estimate for the item "Research courses are difficult" indicates that it has a somewhat weaker relationship with the latent factor Research anxiety. Finally, the standardized estimates for Positive research predispositions ranged from 0.84 to 0.93 .

There was a positive relationship between the latent factors Research usefulness and Positive research predispositions (standardized estimate $=0.49, p<0.01$ ). This indicates that students who confirm the usefulness of research also more frequently show positive research predispositions. The results indicate no statistically-significant relationship 


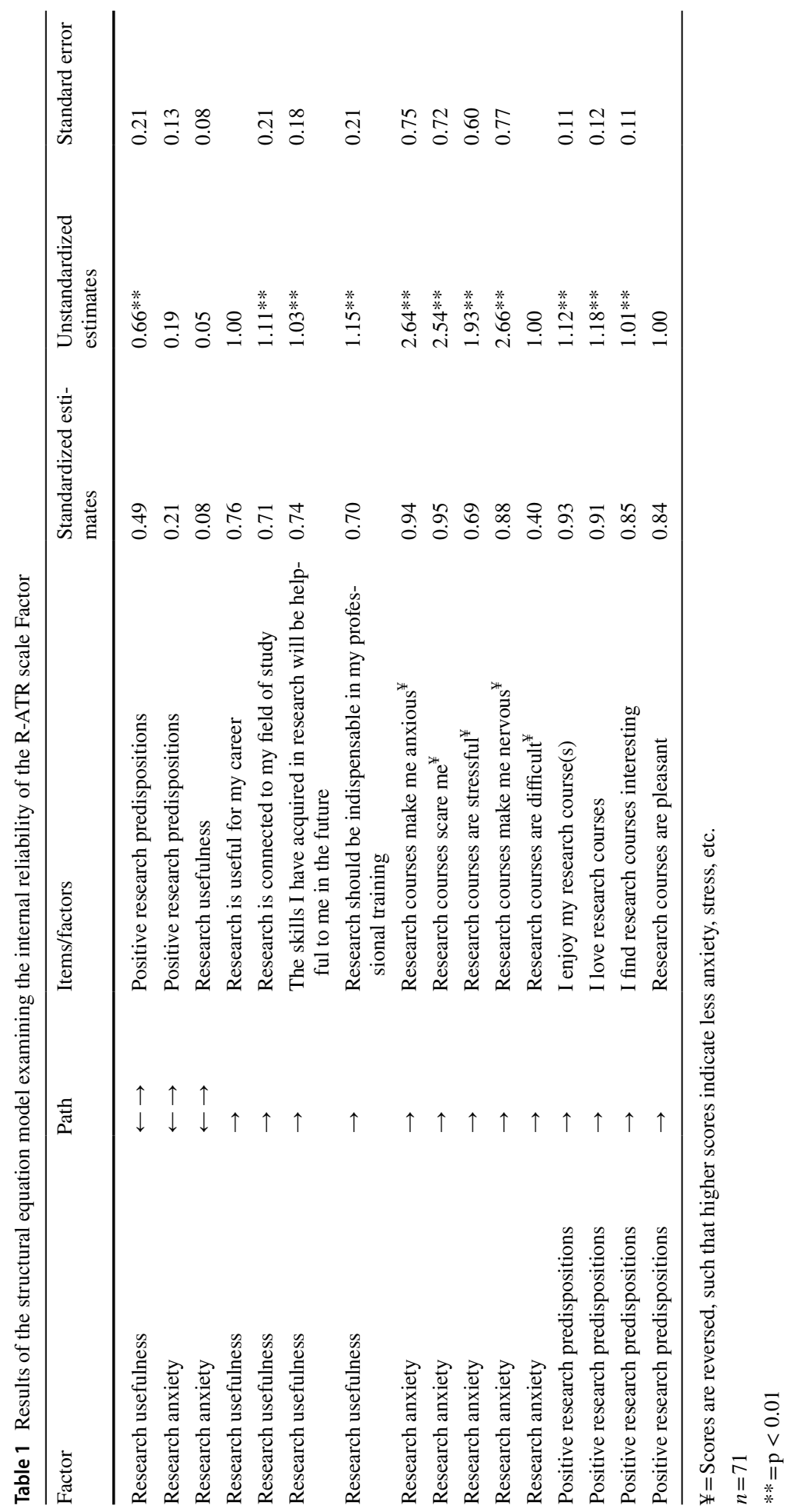


Table 2 Means and standard deviations for 13 statements

\begin{tabular}{llll}
\hline Statement & Mean & SD & $N$ \\
\hline Research usefulness $(\alpha=0.81)$ & & & \\
Research is useful for my career & 5.38 & 1.18 & 77 \\
Research is connected to my field of study & 4.85 & 1.50 & 75 \\
The skills I have acquired in research will be & 5.26 & 1.26 & 77 \\
$\quad$ helpful to me in the future & & & \\
Research should be indispensable in my pro- & 4.92 & 1.49 & 76 \\
$\quad$ fessional training & & & \\
Total score research usefulness & 5.10 & 1.10 & 76 \\
Research anxiety ( $\alpha=0.89)$ & & & \\
Research courses make me anxious* & 5.08 & 1.72 & 79 \\
Research courses scare me* & 5.10 & 1.63 & 79 \\
Research courses are stressful* & 3.87 & 1.75 & 79 \\
Research courses make me nervous* & 4.76 & 1.83 & 79 \\
Research courses are difficult* & 4.03 & 1.52 & 78 \\
Total score research anxiety* & 4.56 & 1.41 & 79 \\
Positive research predispositions $(\alpha=0.93)$ & & & \\
I enjoy my research course(s) & 3.68 & 1.70 & 79 \\
I love research courses & 3.56 & 1.87 & 77 \\
I find research courses interesting & 4.16 & 1.73 & 79 \\
Research courses are pleasant & 3.76 & 1.69 & 79 \\
Total score positive research predispositions & 3.79 & 1.59 & 79 \\
\hline
\end{tabular}

Responses range from (1) Strongly Disagree to (7) Strongly Agree, except for recoded items indicated with*. A higher value indicates a more-positive attitude

$\mathrm{SD}=$ Standard deviation

between Research anxiety and Positive research predispositions (standardized estimate $=0.21, p=0.14$ ) and between Research anxiety and Research usefulness (standardized estimate $=0.08, p=0.55$ ).

For each of the three theorized latent factors, Cronbach's alpha coefficient was calculated to indicate the internal reliability of the constituting items. The value of alpha for the three factors was $0.81,0.89$ and 0.93 for Research usefulness, Research Anxiety and Positive research predispositions, respectively. This result is satisfactory. All results taken into account, it can be concluded that the internal reliability of the R-ATR scale was confirmed in a Dutch second-year architecture student sample.

\section{Attitude of Dutch second-year architecture students towards research courses and perceptions of usefulness, anxiety towards and positive feelings regarding these courses}

The second research question involved the attitude of second-year architecture students towards research courses. The mean scores and standard deviations for the 13 items are presented in Table 2. The items are recoded so that a higher value indicates a more positive attitude. Thus, a higher score for the items related to Research Anxiety indicate less anxiety 


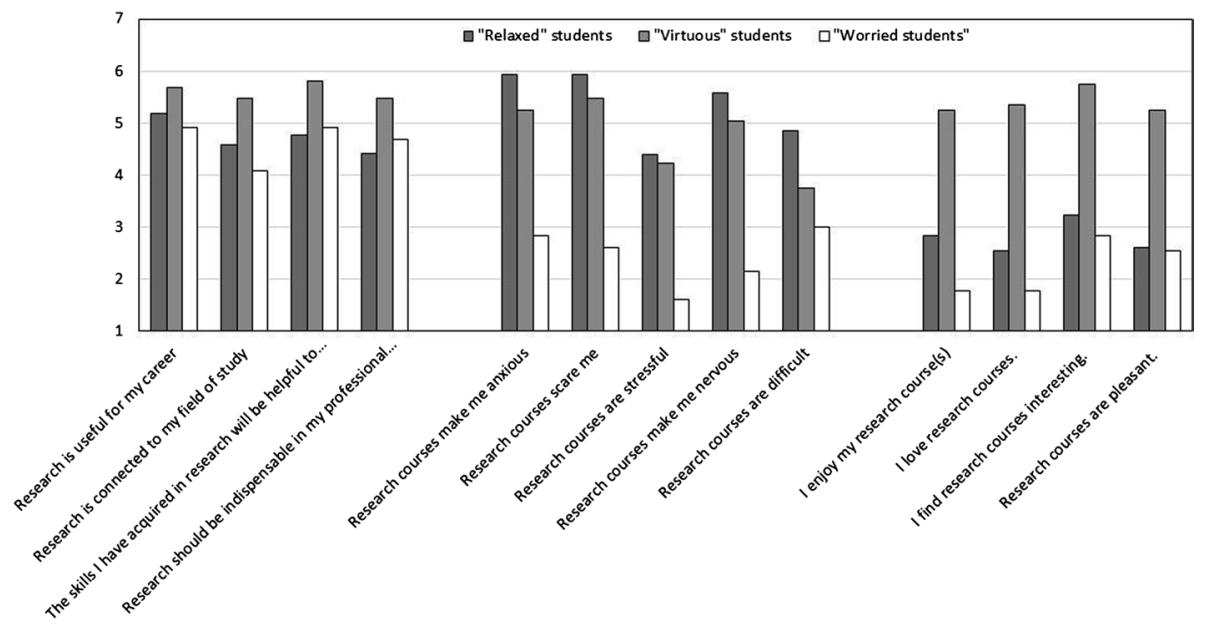

Fig. 1 Mean item scores for Relaxed, Virtuous and Worried clusters of students

and stress. The answering categories range from 1 (Strongly Disagree) to 7 (Strongly Agree). A value of 4 therefore indicates a neutral attitude; mean scores below 4 indicate a (somewhat) negative attitude and those above 4 indicate a (somewhat) positive attitude.

The highest mean scores generally were found for items belonging to the domain of Research usefulness, especially the usefulness of research for the students' future career. The high mean scores for the items on anxiety and fear in the domain of Research anxiety show that Dutch architecture students generally do not get frightened by research courses (with scores recoded so that a higher score implies less anxiety and fear). However, to some extent, students did find research courses stressful and difficult. The most-positive association with research courses was that they can be interesting. Students expected to experience relatively little love, enjoyment or pleasure with regard to their research courses.

Because the value for Cronbach's alpha was satisfactory for each of the three factors, the scores of the individual items that make up a particular factor can be averaged for a total scale score. Scale scores were calculated for all respondents who had no more than one missing answer for a particular scale. The mean scale score for Research usefulness (5.10 averaged over four items) is the highest, indicating that the students agree most with items about the usefulness of research courses. The mean scale score for Research anxiety (4.57 averaged over five items) is somewhat lower but still indicates a positive attitude. The mean scale score for Positive research dispositions (3.79 averaged over four items) is the lowest and, with a mean below 4, suggests that students generally did not expect to derive much pleasure from undertaking research courses.

A TwoStep factor analysis was performed for the 13 items to explore whether there were groups of students with similar attitudes towards research courses. The analysis revealed three different clusters of students (cluster 1: $n=26,37 \%$; cluster 2: $n=32,45 \%$; cluster 3 : $n=13,18 \%$ ). The results, presented as mean item scores for the three clusters of students, are shown in Fig. 1. The two most-important items for the clustering were on enjoyment and love for research courses, followed by items on research courses being interesting and pleasant. These four items are all part of the scale of Positive research predispositions. The items that were part of the scale of Research anxiety were next in importance and the items that belong to Research usefulness were the least important for the clustering. 
As Fig. 1 shows, the three clusters of students did not differ much from each other with regard to Research usefulness. However, the clusters did differ with regard to Research anxiety and Positive research predispositions. The first cluster of students (labeled Relaxed students) scored highest on the Research Anxiety items, indicating that they did not worry too much about research courses. At the same time, these students scored relatively low on Positive research predispositions. These students were not scared by research courses but also definitely did not like them. The second cluster of students (labeled Virtuous students) scored highest on the items on Research usefulness and Positive research predispositions. Apparently, students who appreciate the usefulness of research also more frequently show positive research predispositions, an effect that was also observed in the Structural Equation Modelling analysis. Furthermore, these students also did not fear research courses, albeit to a lesser extent than the Relaxed students (cluster 1). Finally, the third cluster (labeled Worried students) comprised students who definitely do not enjoy research courses and who generally experience more anxiety and stress than other students.

In summary, Dutch second-year architecture students generally had a slightly-positive attitude towards research courses. They acknowledged the importance of these types of courses for their future career and they found these courses interesting. Nevertheless, at the same time, research courses also induced stress and many students did not expect to experience much pleasure and enjoyment from doing research courses.

\section{Is attitude related to age and gender?}

The third research question involved whether attitude is related to age and gender. Pearson correlation coefficients for the relationship between age and each of the 13 items ranged between $-0.04(p=0.74)$ for "Research courses scare me" and $0.23(p=0.04)$ for "I enjoy my research course(s)". Older students might enjoy research courses somewhat more than younger students do, but the relationship is rather weak. The correlations between age and Research usefulness, Research Anxiety and Positive research predispositions were 0.15 $(p=0.19), 0.02(p=0.87)$ and $0.15(p=0.19)$, respectively. These correlations are weak and not statistically significant. ANOVA was used to examine whether the three clustered groups (Relaxed, Virtuous and Worried) differ with regard to age, but this turned out not to be the case $\left(F_{(2,68)}=0.19, p=0.83, n=71\right)$. Thus, in general, this study has identified no relationship between age and attitude towards research courses.

Next, the relationship between gender and the 13 items was examined. An independent sample $t$-test was used to compare males and females on each of the 13 items. The Bonferroni correction was applied because of multiple comparisons $(0.05 / 13=0.004)$. In general, women had a somewhat higher mean score on items related to Research usefulness and Positive research predispositions, but they generally had a somewhat lower mean score on items related to Research anxiety. However, none of the items reached statistical significance, except for "Research should be indispensable in my professional training". Women $($ mean $=5.33, n=42)$ turned out to be more positive than men (mean $=4.36$, $n=33)\left(t_{(73)}=-2.94, p=0.004\right)$.

Results for the relationship between scale scores and gender are shown in Table 3 . The mean total scores again suggest that women were somewhat more positive than men on Research usefulness and Positive research predispositions, but less positive with regard to Research anxiety. An independent sample $t$-test showed a statistically-significant result for Research usefulness only $\left(t_{(73)}=-2.51, p=0.01, n=75\right)$. Finally, a $\chi^{2}$ test was used to examine whether the three clustered groups (Relaxed, Virtuous and Worried) differed with 
Table 3 Scale means and standard deviations for male and female respondents

\begin{tabular}{|c|c|c|c|c|c|c|}
\hline \multirow[t]{2}{*}{ Scale } & \multicolumn{3}{|c|}{$\begin{array}{l}\text { Male respond- } \\
\text { ents }\end{array}$} & \multicolumn{3}{|c|}{$\begin{array}{l}\text { Female respond- } \\
\text { ents }\end{array}$} \\
\hline & Mean & SD & $n$ & Mean & SD & $n$ \\
\hline Research usefulness* & 4.73 & 1.19 & 31 & 5.35 & 0.96 & 44 \\
\hline Research anxiety & 4.69 & 1.39 & 34 & 4.43 & 1.43 & 44 \\
\hline Positive research predispositions & 3.44 & 1.66 & 34 & 4.01 & 1.48 & 44 \\
\hline
\end{tabular}

$* p=0.01$

SD: Standard deviation

regard to gender. The percentage of women was somewhat lower in the Relaxed students group (46\%) than in the other two groups (64 and 61\%), but the difference was not statistically significant $\left(\chi^{2}=2.07, p=0.35, n=70\right)$.

In summary, it can be concluded that the research attitude of female respondents did not differ statistically significantly from that of male respondents, except for Research usefulness. Female respondents had a somewhat more-positive attitude than males with regard to the usefulness of doing research and undertaking research courses.

\section{Discussion, limitations and future suggestions}

This study focused on the attitude of Dutch second-year bachelor architecture students towards research courses by using the Revised-Attitudes Towards Research scale (R-ATR; Papanastasiou, 2014). The first research question focused on the internal reliability of the R-ATR scale, with results showing that the reliability of the three scales was quite satisfactory, with values ranging from 0.81 to 0.93 . Furthermore, structural equation modelling analysis showed an acceptable fit of the model (RMSEA $=0.069)$. All items loaded in a satisfactory way on their intended factors, except for the item "Research courses are difficult". In the study by Papanastasiou (2014), this item also has the lowest standardized estimate on the Anxiety scale. Comparing the meaning of this item with the other items within the factor of Research Anxiety reveals a subtle difference. "Research courses are difficult" is believed to have more of a cognitive nature, whereas anxiety, stress and nervousness are of an emotional nature. One can find something difficult without being emotionally affected by it. Perhaps this can explain the inferior fit of the difficulty item within the factor of Research Anxiety.

The second research question focused on the attitude of Dutch second-year bachelor architecture students towards research courses. Students generally had a slightly-positive attitude towards research courses, especially for the usefulness of research for their future career. Students found research courses somewhat stressful and difficult, but courses did not scare them. Students also believed that research courses can be interesting to some extent, but they hardly expected to experience love, enjoyment or pleasantness concerning their research courses.

A comparison with the results of the study by Papanastasiou (2014) shows that students at our faculty generally had a more-positive attitude towards research courses. More specifically, students experienced less stress and anxiety and had somewhat more appreciation 
of the usefulness of research courses and more-positive research predispositions. Nevertheless, these results should be carefully interpreted because differences between the two studies also could be explained by differences in student samples (e.g. type of study, sociodemographic characteristics and cultural background) and by methodological issues, such as the translation of the questionnaire.

A cluster analysis identified an interesting pattern with three groups of students, which we labeled Virtuous students (45\%), Relaxed students (37\%) and Worried students (18\%). This result suggests that an approach for improving the attitude towards research courses must also be differentiated. Some students will benefit from an emotional approach based on reducing feelings of anxiety and stress, whereas other students might be shown that doing research and following research courses could actually be fun. Yet other students could benefit from more information about the usefulness of research courses for their future career. Note that these labels only apply to the students' attitude towards research courses and not to their other study activities. Furthermore, because the cluster analysis was exploratory, further studies should examine whether the results can be replicated and whether the labels can be validated using some external criterion.

The third research question focused on whether the attitude towards research courses was related to age and gender. Our study did not show a relationship between age and attitude, which contradicts Zan and Martino (2007), Siemens et al. (2010) and Shaukat et al. (2014) who found that age was positively related to a more-appreciative attitude towards research courses. Our finding of a statistically nonsignificant relationship between attitude and age might be explained by the relative homogeneity of the student sample regarding study level and age. Students were in the second year of their studies and their age ranged between 19 and 29 years, with one exception of a student aged 47 years. The narrow range reduces the effect of age. Besides, Murtonen (2005) also did not find a statistically significant difference in attitude towards research for a sample consisting of first, third and fourthyear Finnish students.

Male and female second-year architecture students did not differ with regard to Research Anxiety and Positive research predispositions, a result resembling the findings reported by Shaukat et al. (2014). Furthermore, we found that female students considered research to be more useful than male students did. This finding contrasts with studies by Deepa (2014), Shaukat et al. (2014) and Maqsood et al. (2019), who found that men generally were somewhat more positive towards research (usefulness) than females. Shaukat et al. (2014) argue that men might prefer courses such as mathematics, statistics and economics and might prefer professions that demand advanced skills in mathematics and research, such as business, management and accounting. Our results thus contradict this line of argumentation. The admission criteria of the Architecture, Urbanism \& Building Sciences undergraduate program at TU Delft require that students have completed high-school final examinations in physics and mathematics. This might explain why the research attitude of our female students was at least as positive as that of male students.

This study has some limitations. The response rate was quite low (17\%) for various reasons. First, some students who had enrolled did not actually participate in the course for various reasons. Second, some students $(n=110)$ enrolled in the course only because they had to repeat the statistics examination on which they had failed the previous year. In both of the aforementioned cases, students might be less motivated to fill in the questionnaire. Third, because all modules of the curriculum are evaluated on a regular basis, students might have become somewhat tired of completing yet another survey. Fourth, the invitation was send by mail. Many students do not read their university mail on a regular basis - at least not before the start of the course - and therefore they might have missed the 
opportunity to fill out the survey. The low response rate brings into question the generalizability of the results because the students who completed the questionnaire might not be representative for the population of second-year architecture students. Although the sample and population did not differ in age (mean age sample: 20.6; mean age population: 20.0), there was a small difference with regard to gender. The sample contained relatively more female students $(56 \%)$ than the population $(50 \%)$. We do not know whether sample and population differed on other aspects. For example, it cannot be ruled out that only highlymotivated or overly-positive students completed the survey (albeit 37\% of the sample were labelled as 'relaxed' students and $18 \%$ as 'worried' students). We also do not know the implication of this limitation for our results (e.g. whether highly-motivated students were more present among female students), which might explain the more-positive attitude towards research usefulness in this group.

A related limitation of the current study is the convenience sample: we sampled bachelor architecture students from one university only and from one year only (second year). This limits the generalizability of our results and also limits comparison of our findings with those of Papanastasiou (2014), because the settings differ in so many ways. However, the finding that the underlying structure of the R-ATR scale can be reproduced in a different setting enhances claims with regard to its internal reliability. Another limitation is that we had no information on how well the students performed in the course. We assume that a positive attitude is related to a higher grade but, unfortunately, we could not actually examine this. This should be considered in a future study. Finally, we only examined one aspect that might influence students' mastering of research courses, namely, attitude. Other affective aspects, such as interest, perceptions, self-confidence and motivation were not included. However, Ebenezer et al. (2020) argue that attitude is the most-important construct of the affective domain for influencing science education. Despite the limitations, we believe that our findings provide valuable insights into the attitude of our second-year student population and give us tools for improving attitude and contributing to students being better able to master the material.

What information has the study provided that can be used to improve education in order to stimulate the development of a positive attitude towards research courses? First, because students generally acknowledged the usefulness of research courses for their study or further career, emphasizing the importance of research might not have priority; but sharing this insight with teaching staff might be. Second, research courses can be stressful and difficult for students. Making the research courses more in line with the student expectations and earlier experiences, and providing a research-friendly and supportive environment, might improve the attitude of students towards academic skills and research courses. Third, we have to think about how we can make research courses more interesting to students and how to make them more enjoyable without losing sight of the scientific depth of our course. Teaching could include new media, videos, serious and educational games and blended learning.

We would like to continue to better understand the attitudes and experiences of our students in relation to doing research, particularly how they change and develop over time within our three-year undergraduate program, but also from bachelor to master. We think there might be interesting differences (in attitudes, expectations and experiences) between students from our different master tracks which focus more on design like Architecture and Landscape architecture, on engineering like Building technology and Geomatics, and on planning like Urbanism and Management in the built environment. These kinds of insights could help to support and align decisions on curriculum renewal and development, both in undergraduate and graduate programs. Furthermore, because Murtonen (2005) argues that 
students' attitudes towards research might be formed before or right after the start of their studies, it would be interesting to examine the attitude towards research courses just after the start of the first year. Detecting and, if possible, reducing a negative attitude at an early stage could help students in their further academic career to put into practice the learned research skills not only in the current program but also in their final research project at the end of the bachelor study. Last but not least, because previous research has shown that attitude towards conducting research is related to the intention to use research in future work (Griffioen, 2019), improving attitude might ultimately enhance the use of research activities in the daily practice of architects.

Open Access This article is licensed under a Creative Commons Attribution 4.0 International License, which permits use, sharing, adaptation, distribution and reproduction in any medium or format, as long as you give appropriate credit to the original author(s) and the source, provide a link to the Creative Commons licence, and indicate if changes were made. The images or other third party material in this article are included in the article's Creative Commons licence, unless indicated otherwise in a credit line to the material. If material is not included in the article's Creative Commons licence and your intended use is not permitted by statutory regulation or exceeds the permitted use, you will need to obtain permission directly from the copyright holder. To view a copy of this licence, visit http://creativecommons.org/licenses/by/4.0/.

\section{References}

Aguilera, D., \& Perales-Palacios, F. J. (2020). What effect do didactic interventions have on students' attitudes towards science? A meta-analysis. Research in Science Education, 50, 573-597.

Ashaari, N. S., Judi, H. M., Mohamed, H., \& Wook, T. M. T. (2011). Students' attitude towards statistics course. Procedia Social and Behavioral Sciences, 18, 287-294.

Byrne, Z. S., Weston, J. W., \& Cave, K. (2020). Development of a scale for measuring students' attitudes towards learning professional (i.e. soft) skills. Research in Science Education, 50, 1417-1433.

Coetzee, S., \& van der Merwe, P. (2010). Industrial psychology students' attitudes towards statistics. SA Journal of Industrial Psychology, 36(1), 1-8.

Deepa, C. K. (2014). Attitude among college students towards research in Coimbatore city. Research Expo International Multidisciplinary Research Journal, 4(4), 37-42.

DeVaney, T. A. (2010). Anxiety and attitude of graduate students in on-campus vs. online statistics courses. Journal of Statistics Education, 18(1), 1-7.

Eagly, A. H., \& Chaiken, S. (1993). The psychology of attitudes. Harcourt Brace.

Ebenezer, J., Kaya, O. N., \& Kassab, D. (2020). High school students' reasons for their science dispositions: Community-based innovative technology-embedded environmental research projects. Research in Science Education, 50, 1341-1365.

Field, A (2009). Discovering statistics using SPSS (3rd edition). Sage

Griffioen, D. M. E. (2019). The influence of undergraduate students' research attitudes on their intentions for research usage in their future professional practice. Innovations in Education and Teaching International, 56(2), 162-172.

Griffith, J. D., Adams, L. T., Gu, L. L., Hart, C. L., \& Nichols-Whitehead, P. (2012). Students' attitudes toward statistics across the disciplines: A mixed-method approach. Statistics Education Research Journal, 11(2), 45-56.

Hannigan, A., Hegarty, A. C., \& McGrath, D. (2014). Attitudes towards statistics of graduate entry medical students: The role of prior learning experiences. BMC Medical Education, 14(70), 1-7.

Kennedy, J. P., Quin, F., \& Lyons, T. (2020). The keys to STEM: Australian year 7 students' attitudes and intentions towards science, mathematics and technology courses. Research in Science Education, 50(5), 1805-1832.

Leedy, P. D., \& Ormrod, J. E. (2010). Practical research: Planning and design (9th ed.). Pearson Education Inc.

Lousberg, L., Rooij, R., Jansen, S., van Dooren, E., Heintz, J., \& van der Zaag, E. (2019). Reflection in design education. International Journal of Technology and Design Education. https://doi.org/10.1007/ s10798-019-09532-6 
Maqsood, Z., Jabeen, S. H., Chaudhry, N. R., \& Sardar, I. (2019). Attitude towards research of university students: A multivariate analysis. Pyrex Journal of Educational Research and Reviews, 4(3), 37-43.

Murtonen, M. (2005). University students' research orientations: Do negative attitudes exist toward quantitative methods? Scandinavian Journal of Educational Research, 49(3), 263-280.

Nguyen, T. H., Newby, M., \& Skordi, P. (2015). Development and use of an instrument to measure students' perceptions of a business statistics learning environment in higher education. Learning Environments Research, 18, 409-424.

Oguan, F. E., Jr., Bernal, M. M., \& Pinca, M. C. D. (2014). Attitude and anxiety towards research, its influence on the students' achievement in the course. Asian Journal of Management Sciences and Education, 3(4), 165-172.

Papanastasiou, E. C. (2005). Factor structure of the 'Attitude toward Research' scale. Statistics Education Research Journal, 4(1), 16-26.

Papanastasiou, E. C. (2014). Revised attitudes towards research scale (R-ATR). A first look at its psychometric properties. Journal of Research in Education, 24(2), 146-159.

Shaukat, S., Siddiquah, A., Abiodullah, M., \& Akbar, R. A. (2014). Postgraduate students' attitudes towards research. Bulletin of Education and Research, 36(1), 111-122.

Siemens, D. R., Punnen, S., Wong, J., \& Kanji, N. (2010). A survey on the attitudes towards research in medical school. BMC Medical Education, 10(1), 1-7.

Strobl, C., Dittrich, C., Seiler, C., Hackensperger, S., \& Leisch, F. (2010). Measurement and predictors of a negative attitude towards statistics among LMU students. In T. Kneib \& G. Tutz (Eds.), Statistical modelling and regression structures (pp. 217-230). Springer-Verlag.

Tseng, K. H., Chang, C. C., Lou, S. J., \& Chen, W. P. (2013). Attitudes towards science, technology, engineering and mathematics (STEM) in a project-based learning (PjBL) environment. International Journal of Technology and Design Education, 23, 87-102.

TU Delft. (2020). Bachelor's degree programme. https://www.tudelft.nl/en/architecture-and-the-built-envir onment/study/bachelors-degree-programme/. Accessed 8 July 2020

Zan, R., \& Di Martino, P. (2007). Attitude toward mathematics: Overcoming the positive/negative dichotomy. TMME Monograph, 3, 157-168.

Publisher's Note Springer Nature remains neutral with regard to jurisdictional claims in published maps and institutional affiliations. 